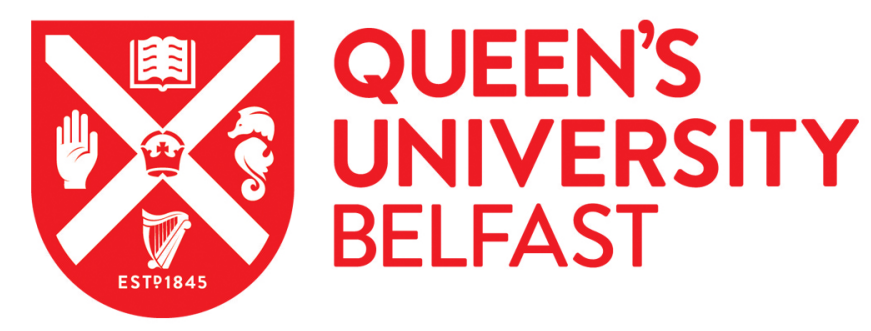

\title{
Controlling Levonorgestrel Binding and Release in a Multi-Purpose Prevention Technology Vaginal Ring Device
}

Murphy, D. J., Boyd, P., McCoy, C. F., Kumar, S., Holt, J. D. S., Blanda, W., Brimer, A. N., \& Malcolm, R. K. (2016). Controlling Levonorgestrel Binding and Release in a Multi-Purpose Prevention Technology Vaginal Ring Device. Journal of Controlled Release : official journal of the Controlled Release Society, 226, $138-147$. https://doi.org/10.1016/j.jconrel.2016.02.020

Published in:

Journal of Controlled Release : official journal of the Controlled Release Society

\section{Document Version:}

Peer reviewed version

Queen's University Belfast - Research Portal:

Link to publication record in Queen's University Belfast Research Portal

Publisher rights

(c) 2016 Elsevier. This manuscript version is made available under the CC-BY-NC-ND 4.0 licensehttp://creativecommons.org/licenses/by-ncnd/4.0/,which permits distribution and reproduction for non-commercial purposes, provided the author and source are cited.

\section{General rights}

Copyright for the publications made accessible via the Queen's University Belfast Research Portal is retained by the author(s) and / or other copyright owners and it is a condition of accessing these publications that users recognise and abide by the legal requirements associated with these rights.

Take down policy

The Research Portal is Queen's institutional repository that provides access to Queen's research output. Every effort has been made to ensure that content in the Research Portal does not infringe any person's rights, or applicable UK laws. If you discover content in the Research Portal that you believe breaches copyright or violates any law, please contact openaccess@qub.ac.uk. 
1

\title{
Controlling Levonorgestrel Binding and Release in a Multi- Purpose Prevention Technology Vaginal Ring Device
}

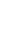

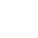

\author{
Diarmaid J. Murphy, ${ }^{\dagger}$ Peter Boyd, ${ }^{\dagger}$ Clare F. McCoy, ${ }^{\dagger}$ Sandeep Kumar, ${ }^{\dagger}$ \\ Jonathon D. S. Holt, ${ }^{\ddagger}$ Wendy Blanda, ${ }^{\ddagger}$ Andrew N. Brimer, ${ }^{\ddagger}$ R. Karl Malcolm ${ }^{*}{ }^{\dagger}$
}

${ }^{\dagger}$ School of Pharmacy, Queen's University Belfast, Belfast BT9 7BL, United Kingdom

${ }^{\ddagger}$ International Partnership for Microbicides, Silver Spring, Maryland, United States.

(1)

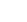

\footnotetext{
* Corresponding author / reprints: R. Karl Malcolm, Tel.: +44 (0)28 9097 2319; E-mail: k.malcolm@qub.ac.uk
}

3 Keywords: vaginal ring; silicone elastomer; hydrosilylation; controlled release; drug delivery;

4
implantable devices 


\section{ABSTRACT}

16 Despite a long history of incorporating steroids into silicone elastomers for drug delivery

17 applications, little is presently known about the propensity for irreversible drug binding in these

18 systems. In this study, the ability of the contraceptive progestin levonorgestrel to bind

19 chemically with hydrosilane groups in addition-cure silicone elastomers has been thoroughly

20 investigated. Cure time, cure temperature, levonorgestrel particle size, initial levonorgestrel

21 loading and silicone elastomer type were demonstrated to be key parameters impacting the

22 extent of levonorgestrel binding, each through their influence on the solubility of levonorgestrel

23 in the silicone elastomer. Understanding and overcoming this levonorgestrel binding

24 phenomenon is critical for the ongoing development of a number of drug delivery products,

25 including a multi-purpose technology vaginal ring device offering simultaneous release of

26 levonorgestrel and dapivirine - a lead candidate antiretroviral microbicide - for combination

27 HIV prevention and hormonal contraception. 


\section{1. Introduction}

29 Silicone elastomers have been widely used in controlled release drug delivery applications since

30 Dzuik and Cook first demonstrated in 1966 that various steroid molecules were capable of

31 effectively permeating and releasing from silicone rubber capsules subcutaneously implanted in

32 ewes [1]. Numerous steroid-releasing silicone elastomer devices, including subdermal implants,

33 vaginal rings and intrauterine systems, have since reached market (Table 1). The past ten years

34 have seen considerable interest in silicone elastomer vaginal ring technology for controlled

35 release of antiretroviral (ARV) drug molecules for prevention of sexual transmission of human

36 immunodeficiency virus (HIV) (Table 1) [2-9]. The International Partnership for Microbicides

37 (IPM) and the Microbicide Trial Network (MTN) are currently in Phase III clinical trials in Africa

38 with a matrix-type silicone elastomer vaginal ring developed by IPM. This ring device provides

39 controlled release of dapivirine (Figure 1A), a non-nucleoside reverse transcriptase inhibitor,

40 over 28 days and has already been shown to be safe and well tolerated in vivo. If successful, the

41 dapivirine ring will likely provide both further impetus and a viable technology platform for

42 development of multi-purpose prevention technologies (MPTs) aimed at combining HIV

43 prevention with prevention of unintended pregnancy and prevention/treatment of other

44 sexually transmitted infections (STIs) through use of a single formulation or drug-device

45 combination product [10-13]. Many of the MPT products currently undergoing development

46 have prioritised use of levonorgestrel (Figure 1A) as the contraceptive hormone component,

47 based on its historical record of safety and efficacy [12-14]. 
51 VR - vaginal rings

\begin{tabular}{|c|c|c|c|c|c|}
\hline Product name & Product type & Drug(s) & Indication / duration of action & Developer & Stage \\
\hline Norplant ${ }^{\circledR}$ & $\begin{array}{l}\text { reservoir-type } \\
\text { subdermal implant }\end{array}$ & levonorgestrel & female contraception / 5 years & Population Council & Discontinued \\
\hline $\begin{array}{l}\text { Jadelle }^{\circledR} \\
\text { (Norplant II) }\end{array}$ & $\begin{array}{l}\text { reservoir-type } \\
\text { subdermal implant }\end{array}$ & levonorgestrel & female contraception / 5 years & Population Council & Marketed \\
\hline Mirena ${ }^{\circledR}$ & $\begin{array}{l}\text { reservoir-type } \\
\text { intrauterine system }\end{array}$ & levonorgestrel & female contraception / 5 years & Bayer & Marketed \\
\hline Skyla $^{\circledR}$ & $\begin{array}{l}\text { reservoir-type } \\
\text { intrauterine system }\end{array}$ & levonorgestrel & female contraception / 5 years & Bayer & Marketed \\
\hline Femring $^{\circledR}$ & reservoir-type VR & $17 \beta$-estradiol-3-acetate & estrogen replacement therapy / 3 months & Warner Chilcott & Marketed \\
\hline Estring $^{\circledR}$ & reservoir-type VR & $17 \beta$-estradiol & estrogen replacement therapy / 90 days & Pfizer & Marketed \\
\hline Progering $^{\circledR}$ & matrix-type VR & progesterone & female contraception / 1 year & Population Council & $\begin{array}{l}\text { Marketed (South } \\
\text { America only) }\end{array}$ \\
\hline Fertiring $^{\circledR}$ & matrix-type VR & progesterone & $\begin{array}{l}\text { in vitro fertilization / hormone } \\
\text { replacement therapy / } 3 \text { months }\end{array}$ & Population Council & Marketed \\
\hline- & matrix-type VR & progesterone & luteal phase support & Italfarmaco & Phase I/II \\
\hline- & matrix-type VR & progesterone & luteal phase support & TEVA & Discontinued \\
\hline- & reservoir-type VR & oxybutynin & overactive bladder & TEVA & Discontinued \\
\hline- & reservoir-type VR & $\begin{array}{l}\text { nestorone and ethinyl } \\
\text { estradiol }\end{array}$ & female contraception & Population Council & Phase III \\
\hline- & matrix-type VR & dapivirine & HIV prevention / 30 days & IPM & Phase III \\
\hline- & matrix-type VR & dapivirine and maraviroc & HIV prevention / 30 days & IPM & Phase I \\
\hline- & matrix-type VR & $\begin{array}{l}\text { dapivirine and } \\
\text { levonorgestrel }\end{array}$ & HIV prevention / 90 days & IPM & Phase I \\
\hline
\end{tabular}


53 Silicone elastomers for use in medical and pharmaceutical applications are prepared through

54 the chemical crosslinking of functionalised, linear, polydimethylsiloxane molecules. The most

55 important chemical crosslinking mechanisms involve either condensation-cure or addition-cure

56 chemistries. Condensation-cure systems involve the tin-catalysed reaction between hydroxy-

57 terminated polydimethylsiloxane molecules and a tetraalkoxysilane, resulting in the formation

58 of the cured elastomer and an alcohol by-product $[15,16]$. Although the chemistry of this

59 silicone elastomer crosslinking reaction is generally compatible with a very wide range of

60 chemical functional groups, the alcohol produced can be problematic when the incorporated

$61 \mathrm{drug}(\mathrm{s})$ is highly soluble in the alcohol $[17,18]$. Crosslinking of addition-cure silicone elastomer

62 systems relies on the platinum-catalysed hydrosilylation reaction between hydride- and vinyl-

63 functionalised polydimethylsiloxane molecules (Figure 1B). No by-product is formed with this

64 reaction. However, the platinum catalyst is particularly sensitive to poisoning by certain

65 chemical functional groups, most notably organotin, organosulfur and certain amine containing 66 compounds. 
A

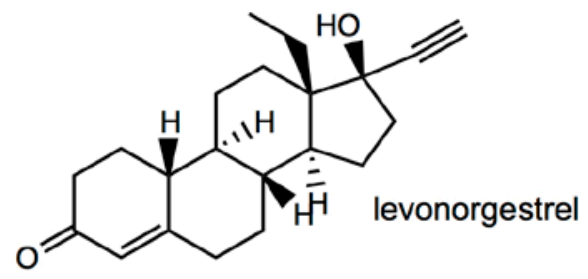<smiles>Cc1cc(C)c(Nc2ccnc(Nc3ccc(C#N)cc3)n2)c(C)c1</smiles>

B
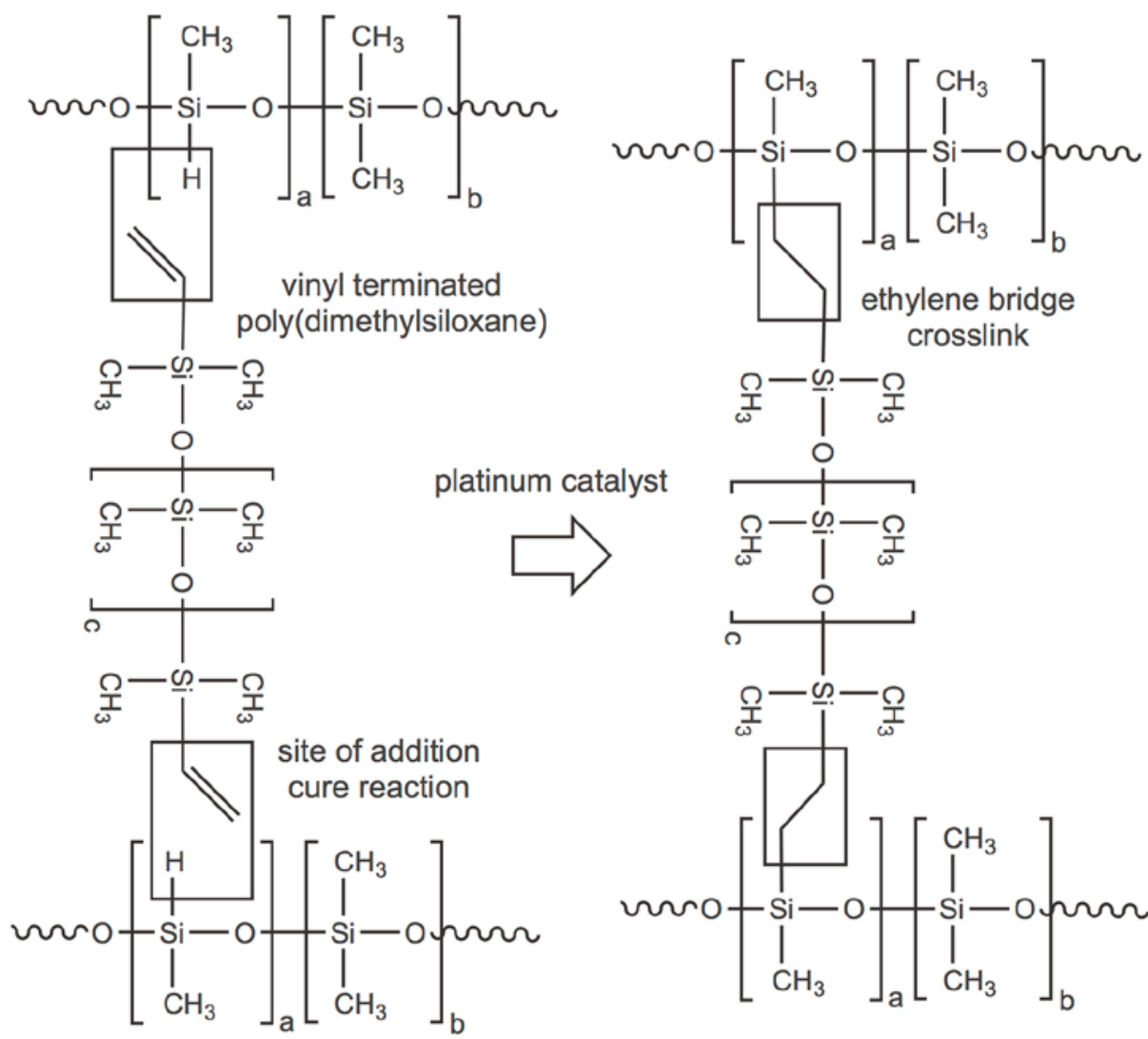

$$
\frac{\rho}{\omega}-\frac{\omega}{0}-\frac{\rho}{\omega}
$$<smiles>CCCCCCCC</smiles>

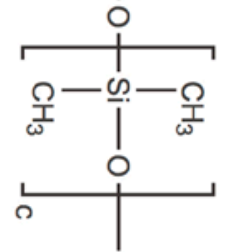<smiles>CO[Ge](C)(O)OC</smiles>

poly(dimethylsiloxaneco-methylhydrosiloxane

C<smiles>[R20][Si]([1H])(C)OCC</smiles><smiles>[R]C([R])=C([R])[R]</smiles><smiles>[R]C([R])([2H])C([R12])([R3])[Si]([R20])(C)OCC</smiles>

hydrosilane residue in a poly(methyl hydrogen)siloxane

alkenyl compound

D<smiles>[R20][Si]([2H])(C)OCC</smiles><smiles>[R]C#C[R]</smiles><smiles>[R]C=C([R9])[Si]([R20])(C)C=CC</smiles>

hydrosilane residue in a poly(methyl hydrogen)siloxane 
68 Figure 1. A - Chemical structures of levonorgestrel and dapivirine. B - Addition-cure

69 mechanism for silicone elastomers showing the platinum-catalysed hydrosilylation reaction

70 between $\mathrm{Si}-\mathrm{H}$ and vinyl groups. $\mathrm{C}-$ General hydrosilylation reaction between the Si-H groups in

71 poly(methyl hydrogen silane) and alkenyl compounds. D - General hydrosilylation reaction

72 between the Si-H groups in poly(methyl hydrogen silane) and alkynyl compounds.

74 It is well established that small molecules containing ethylenic $(C=C)$ and acetylenic $(C \equiv C)$

75 functional groups can undergo hydrosilylation reaction with molecules containing hydrosilane

76 (Si-H) groups (Figures $1 \mathrm{C}$ and 1D, respectively) [19-23]. In general, the alkyne hydrosilylation

77 reaction catalysed by platinum proceeds at a faster rate compared to alkenes, and is less

78 susceptible to many electronic and structural factors that may impede alkene hydrosilylation

79 [19]. Given the large number of steroid molecules containing ethylenic or acetylenic functional

80 groups that have been previously formulated in silicone elastomers, it is rather surprising that

81 only a single article (a 1980 US patent) has reported the potential for covalent binding of such

82 steroids to the silicone elastomer [24]. Furthermore, the patent states that the quantity of drug

83 that reacts with the silicone elastomer is "negligible for the sustained drug release rate". On the

84 contrary, here we report that levonorgestrel, a common contraceptive progestin, reacts with

85 addition-cure silicone elastomer systems such that a very significant fraction of the

86 incorporated levonorgestrel can be irreversibly bonded to the silicone elastomer impacting

87 levonorgestrel release rates. The extent of binding is dependent on the silicone elastomer cure

88 conditions and the particle size of the levonorgestrel material used. Aside from recent U.S.

89 patent applications by IPM $[25,26]$, this issue has not been reported previously for 
90 levonorgestrel, despite its long history of incorporation into addition-cure silicone elastomer

91 drug delivery systems (Table 1). 


\section{2. Methods and Materials}

\section{2.1. Materials}

94 Medical grade, addition-cure silicone elastomers DDU-4320 and MED-4870, condensation-cure

95 silicone elastomer MED-6382, and MED-360 silicone oil were supplied by NuSil Silicone

96 Technology Inc. (Carpinteria, CA, USA). Micronized dapivirine was supplied by S.A. Ajinomoto

97 OmniChem N.V. (Wetteren, Belgium). Micronised levonorgestrel was supplied by CHEMO

98 Group (Saronno, Italy). Non-micronized and sieved fractions of non-micronized levonorgestrel

99 (non-micronised levonorgestrel) were supplied by Tecoland (Irvine, CA, US) and CHEMO Group

100 (Saronno, Italy); except where explicitly stated, non-micronised levonorgestrel in the text refers

101 to material sourced from Tecoland. Particle size data (d10, d50 and d90; measured via laser

102 diffraction) for each of the levonorgestrel materials was provided by the suppliers (Table 2).

103 HPLC-grade acetonitrile, isopropanol and dichloromethane, and phosphoric acid (85\% w/w in 104 water) were purchased from Sigma Aldrich (Gillingham, UK). HPLC-grade water was obtained 105 using a Millipore Direct-Q 3 UV Ultrapure Water System (Watford, UK). 19-norethindrone was 106 supplied by LGM Pharma (Boca Raton, Florida, USA) and used as an internal standard for HPLC. 107 Analytical grade potassium dihydrogen orthophosphate was obtained from VWR (Dublin, 108 Ireland). 
109 Table 2. Influence of levonorgestrel particle size on its recovery from $0.4 \% \mathrm{w} / \mathrm{w}$ levonorgestrel-

110 loaded DDU-4320 silicone elastomer slabs cured at $100^{\circ} \mathrm{C}$ for $90 \mathrm{~s}$. Each levonorgestrel

111 recovery value is the mean of four replicates and reported errors denote standard deviations.

\begin{tabular}{lcc}
\hline levonorgestrel batch & $\begin{array}{c}\text { Particle size } \\
\mathrm{d} 90, \mathrm{~d} 50, \mathrm{~d} 10(\mu \mathrm{m})\end{array}$ & $\begin{array}{c}\text { \% levonorgestrel } \\
\text { recovery }\end{array}$ \\
\hline 1 (micronized) & $6.11,2.18,0.72$ & $41.3 \pm 6.5$ \\
2 (sieved fraction) & $294,81,5$ & $56.7 \pm 5.2$ \\
3 (sieved fraction) & $384,170,6$ & $55.6 \pm 2.8$ \\
4 (non-micronized) ${ }^{*}$ & $542,348,156$ & $98.4 \pm 11.4$ \\
\hline
\end{tabular}

112

* This non-micronized material was supplied by CHEMO.

\subsection{Manufacture of silicone rings and slabs}

Matrix-type, silicone elastomer vaginal rings containing $200 \mathrm{mg}$ micronized dapivirine and 32

117 diameter $\times 7.8 \mathrm{~mm}$ cross-sectional diameter were manufactured by reaction injection molding

118 of active silicone elastomer mixes using a Babyplast 6/10P injection-molding machine in semi-

119 automatic mode fitted with custom, stainless steel, single-cavity injection molds. These rings

120 were cured at $160^{\circ} \mathrm{C}$ for $90 \mathrm{~s}$. Briefly, the appropriate quantities of dapivirine and levonorgestrel

121 powders were added to both Parts A and B of the addition-cure silicone elastomer system MED-

1224870 and mixed at 3000 rpm for 3 min using a SpeedMixer DAC 150 FVZ-K (Synergy Devices,

123 UK). These active premixes were stored at $4^{\circ} \mathrm{C}$ until use. Prior to combining the premixes, they

124 were first hand-mixed with a spatula for $30 \mathrm{~s}$ and then speedmixed for $120 \mathrm{~s}$ at $3000 \mathrm{rpm}$. Equal

125 weights of Part A and Part B active premixes were then combined, handmixed for $30 \mathrm{~s}$, 126 speedmixed for $30 \mathrm{~s}$ at $3000 \mathrm{rpm}$, and then transferred to a $65 \mathrm{cc}$ low-density polyethlyene 127 Semco 220316 cartridge system (Polymer Systems Technology Ltd., Buckinghamshire, UK) that 
operates with the dosing meter fitted to the Babyplast injection molder.

130 Silicone elastomer slabs $(20.0 \times 30.0 \times 2.0 \mathrm{~mm})$ or vaginal rings containing levonorgestrel or

131 dapivirine were also manufactured in a similar fashion using a custom, aluminium, multi-cavity

132 mold fitted to a electrically-heated, laboratory-scale injection molding machine. For rings and

133 slabs prepared using the DDU-4320 silicone elastomer (a low temperature cure system), cure

134 time and temperature were varied between $1.5-120 \mathrm{~min}$ and $60-160^{\circ} \mathrm{C}$, respectively. For slabs

135 prepared with the MED-4870 silicone elastomer (a high temperature cure system), cure time

136 and temperature were varied between $1.5-120 \mathrm{~min}$ and $120-200^{\circ} \mathrm{C}$, respectively.

137 Levonorgestrel-loaded silicone elastomer slabs were also prepared using condensation-cure

138 MED-6382 silicone elastomer using cure conditions of $80^{\circ} \mathrm{C} / 5 \mathrm{~min}$. For some silicone elastomer

139 slabs, the drug powder was first dispersed in MED-360 silicone oil prior to preparing the silicone

140 elastomer premixes.

\section{2.3. Quantification of levonorgestrel by HPLC}

143 Levonorgestrel concentrations were quantified by HPLC using a BDS Hypersil C18, $3 \mu \mathrm{m}$ column

144 (150 x $4.6 \mathrm{~mm}$; Thermo Scientific, UK), fitted with an Analytical Guard Cartridge System

145 (Phenomenex, UK), at $25^{\circ} \mathrm{C}$ on a system comprising a Waters 1525 binary HPLC pump, 717 Plus

146 autosampler, in-line degasser AF unit, and 2487 dual absorbance detector. Isocratic HPLC was

147 performed with a mobile phase of $7.7 \mathrm{mM}$ phosphate buffer, $\mathrm{pH} 3.0$ and acetonitrile (55:45) at

148 flow rate of $1.2 \mathrm{~mL} / \mathrm{min}$ with detection at $240 \mathrm{~nm}$. The retention times of norethindrone

149 (internal standard) and levonorgestrel were 5.2 and $8.2 \mathrm{~min}$, respectively. All chromatograms 
were processed using the supplied Waters Breeze software.

\subsection{In vitro release testing of rings}

153 In vitro levonorgestrel release from vaginal rings $(n=6)$ was assessed over a 15-day period. Each

154 vaginal ring was placed into a glass flask containing $200 \mathrm{~mL}$ of isopropanol (IPA)/water mixture

155 (1:1 volume ratio). This IPA/ $\mathrm{H}_{2} \mathrm{O}$ mixture has been widely used for in vitro release testing of 156 silicone elastomer vaginal rings, since it offers greater solvating power for poorly water-soluble 157 drugs compared with aqueous media, such as simulated vaginal fluid $[2-5,17]$. The volumes of 158 media for release testing were selected based on previously measured solubility values in 1:1 159 IPA/water (LNG $-0.75 \mathrm{mg} / \mathrm{mL}$ at $25^{\circ} \mathrm{C} ; \mathrm{DPV}-0.80 \mathrm{mg} / \mathrm{mL}$ at $\left.37^{\circ} \mathrm{C}\right)$. The flasks were sealed and 160 placed in an orbital shaking incubator (Infors $\mathrm{HT}$ AGCH-4103; 37 ${ }^{\circ} \mathrm{C}, 60 \mathrm{rpm}$, throw $25 \mathrm{~mm}$ ). After $16124 \mathrm{~h}( \pm 15 \mathrm{~min})$, each flask was removed from the incubator and a sample $(2 \mathrm{~mL})$ of the release 162 medium was retained for HPLC analysis. The remaining release medium was discarded and 163 replaced with fresh medium (100 mL IPA: $\mathrm{H}_{2} \mathrm{O}$ ). This sampling procedure was continued on a 164 daily basis, except weekends when $200 \mathrm{~mL}$ of release medium were added to the flasks each 165 Friday so as to maintain sink conditions through the following Monday.

\section{2.5. Levonorgestrel content analysis of manufactured rings and slabs}

168 The total amount of levonorgestrel recoverable from silicone elastomer rings and slabs was 169 determined using a solvent extraction method followed by quantification using HPLC. Each 170 device was weighed, cut into approximately $2 \mathrm{~mm}$ sections, and placed in a $250 \mathrm{~mL}$ screw-top 171 glass flask. $5 \mathrm{~mL}$ of a $2.5 \mathrm{mg} / \mathrm{mL}$ solution of 19-norethindrone in methanol (internal standard) 
172 was added along with $95 \mathrm{~mL}$ of dichloromethane (extraction solvent). The flasks were placed in

173 an orbital shaking incubator $\left(37^{\circ} \mathrm{C}, 60 \mathrm{rpm}\right.$, throw $\left.25 \mathrm{~mm}\right)$ for $72 \mathrm{~h} . \mathrm{A} 2 \mathrm{~mL}$ aliquot of the

174 solution was evaporated to dryness and the residue reconstituted in $10 \mathrm{~mL}$ of methanol before

175 being diluted ten-fold in a mixture of methanol and deionised water prior to analysis by HPLC.

176 Control flasks containing known amounts of a levonorgestrel standard solution were also tested

177 in each set of experiments.

\section{2.6. Drug extraction and swelling studies}

180 Cured silicone elastomer slabs containing $1 \% \mathrm{w} / \mathrm{w}$ loading of either dapivirine, micronised

181 levonorgestrel or non-micronised levonorgestrel were manufactured, extracted with

182 dichloromethane $(100 \mathrm{~mL})$, and then the resulting drug-depleted slabs swollen in $\mathrm{n}$-hexane to

183 assess cross-linking density [27]. A pictorial representation of the experimental method is

184 shown in Figure 2. Briefly, drugs were weighed into the appropriate amounts of part A and part

185 B silicone elastomer and speedmixed for 2 min. Part A and part B active mixes were then hand

186 mixed (10 s), speedmixed (30 s), and then injection molded at $90^{\circ} \mathrm{C}$ for $3 \mathrm{~min}$. These slabs were

187 individually weighed and the weights were recorded $\left(\mathrm{W}_{0}\right)$. These slabs were then placed into

188 screw-top glass flasks containing $45 \mathrm{~mL}$ of dichloromethane. $5 \mathrm{~mL}$ of $500 \mu \mathrm{g} / \mathrm{mL}$ methanolic

189 solution containing norethindrone was added as an internal standard. The flasks were placed in

190 a shaking orbital shaker $\left(37^{\circ} \mathrm{C}, 60 \mathrm{rpm}\right.$, throw $\left.25 \mathrm{~mm}\right)$ and the release medium was sampled

$191(\sim 5 \mathrm{~mL})$ after a period of $72 \mathrm{~h}$. Quantification of drug concentrations in the samples was

192 performed using HPLC-UV. 


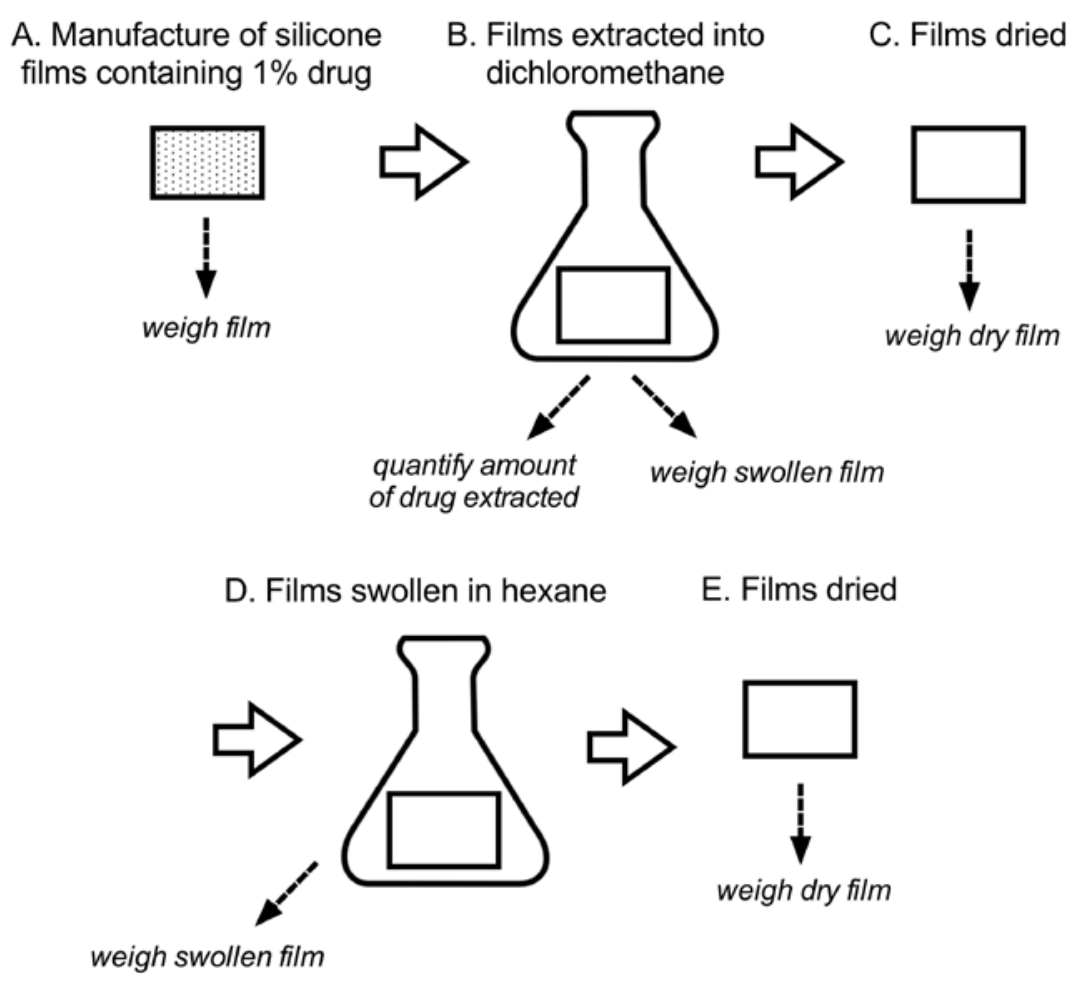

194 Figure 2. Experimental protocol for hexane swelling experiments to assess crosslinking density 195 in drug-loaded silicone silicone silicone slabs.

197 Immediately after drug sampling, the swollen slabs were removed from the dichloromethane, 198 wiped with tissue paper to remove any excess solvent, placed in a tightly closed flasks and 199 weighed $\left(W_{1}\right)$. These slabs were then dried overnight in a fume hood at room temperature, 200 followed by drying at $60^{\circ} \mathrm{C}$ for $1 \mathrm{~h}$. The dry weights of the slabs were recorded $\left(\mathrm{W}_{2}\right)$. The dried 201 slabs were then placed in $50 \mathrm{~mL}$ of $\mathrm{n}$-hexane. As before, the swollen slabs were weighed $\left(\mathrm{W}_{3}\right)$, 202 dried, and weighed again $\left(\mathrm{W}_{4}\right)$. The amount of drug extracted, swelling ratio and total mass 203 extracted from these silicone elastomer slabs in both solvents were calculated (Equations 1 204 4). 
Mass extraction in $\mathrm{CH}_{2} \mathrm{Cl}_{2}=\frac{\left(W_{0}-W_{2}\right)}{W_{2}} \times 100$

\subsection{Oscillatory rheology}

211 Silicone elastomer samples containing 1, 5, 10, 15 and 20\% w/w of dapivirine, micronised or

212 non-micronised levonorgestrel were prepared by adding appropriate quantities of each drug

213 powder to Parts A and B of silicone elastomer DDU-4320. Following mixing with a Speedmixer

214 for $30 \mathrm{~s}$, a sample of each silicone elastomer active mix (1.0 g) was placed onto the lower

215 stationary plate of a TA instruments AR 1500 rotational rheometer, maintained at $25^{\circ} \mathrm{C}$, and the

216 upper plate (40 mm cross-hatch plate) was lowered to produce a gap between the plates of

$2171000 \mu \mathrm{m}$. The time taken from loading of the sample to commencement of the experiment was

218 typically less than $30 \mathrm{~s}$. Each sample was heated to $80^{\circ} \mathrm{C}$ and maintained at that temperature

219 for $15 \mathrm{~min}$ at $10 \mathrm{~Hz}$ oscillation frequency and the storage modulus monitored over $900 \mathrm{~s}$, 220 corresponding to the initial cure period for the silicone elastomer [28]. 


\section{3. Results and Discussion}

\section{3.1. Particle size analysis}

223 Representative digital microscopy images of the four different levonorgestrel materials used in

224 this study (one micronized material, two non-micronized and sieved fractions, and one non225 micronized and non-sieved material) are presented in Figure 3 and clearly illustrate visual 226 differences in the particle size distributions. Quantitative measures of particle size (d10, d50 227 and d90 values) for each of the four materials are also presented in Table 2.

228

229

230

231

232

233

234

235

236

\subsection{In vitro release testing of rings demonstrating bound levonorgestrel}

The mean daily release vs. time and mean cumulative release vs. root time profiles for MED4870 silicone elastomer matrix-type vaginal rings containing $200 \mathrm{mg}$ micronized dapivirine and $32 \mathrm{mg}$ of either micronised levonorgestrel or non-micronised levonorgestrel and cured at 160

${ }^{\circ} \mathrm{C}$ for $90 \mathrm{~s}$ are presented in Figure 4. Dapivirine and non-micronised levonorgestrel are effectively released from the vaginal rings, with relatively high quantities of each drug released on Day 1 ( $6000 \mu \mathrm{g}$ and $\sim 750 \mu \mathrm{g}$ for dapivirine and levonorgestrel, respectively) followed by steadily declining release rates on subsequent days. Dapivirine release was very similar irrespective of the particle size of the levonorgestrel incorporated into the vaginal rings. The lower rate of release observed of non-micronised levonorgestrel from the vaginal rings compared with dapivirine is attributed to both its lower initial loading and its unique molecular permeability characteristics in the silicone elastomer. In general, the daily release profiles are typical of matrix-type vaginal rings containing solid drug dispersed within a non-degradable polymer matrix. The linear cumulative release vs. root time profiles (Figure 4C and 4D) confirm 
243 root time $\left(\mathrm{t}^{1 / 2}\right)$ kinetics, and are indicative of a permeation-controlled mechanism $[29,30]$.

244 However, surprisingly, vaginal rings containing micronised levonorgestrel showed no drug 245 release (Figures 4B and 4D). Repeat experiments confirmed that the correct quantity of 246 micronised levonorgestrel was added to the silicone elastomer premixes and that no 247 levonorgestrel release was observed (repeat data not shown). Based on scant evidence from 248 the literature [24], we hypothesized that all $32 \mathrm{mg}$ micronised levonorgestrel initially 249 incorporated into the vaginal ring formulation had dissolved in the ring matrix and 250 subsequently covalently bonded to the silicone elastomer via a hydrosilylation reaction (Figure 251 1D) between the alkynyl (i.e. ethinyl) group in levonorgestrel (Figure 1A) and the Si-H groups in 252 the silicone elastomer system (Figure 1B). This drug-binding hypothesis was supported by 253 attempting to solvent-extract the levonorgestrel content from the vaginal rings; only $0.5 \%$ 254 levonorgestrel was recovered for vaginal rings containing micronised levonorgestrel compared 255 to $57.3 \%$ for non-micronised levonorgestrel vaginal rings. Dapivirine does not contain alkenyl or 256 alkynyl functional groups (Figure 1A), and therefore is incapable of undergoing hydrosilylation 257 reaction. $96.7 \%$ and $97.7 \%$ of incorporated dapivirine content was recovered from vaginal rings 258 containing $200 \mathrm{mg}$ dapivirine $+32 \mathrm{mg}$ non-micronised levonorgestrel and $200 \mathrm{mg}$ dapivirine + $25932 \mathrm{mg}$ micronised levonorgestrel, respectively. In previous studies, complete recovery of 260 dapvirine was also achieved with rings containing just $25 \mathrm{mg}$ dapvirine, further confirming that 261 dapvirine does not have the chemical functionality required to take part in the hydrosilylation 262 reaction $[4,18]$. 

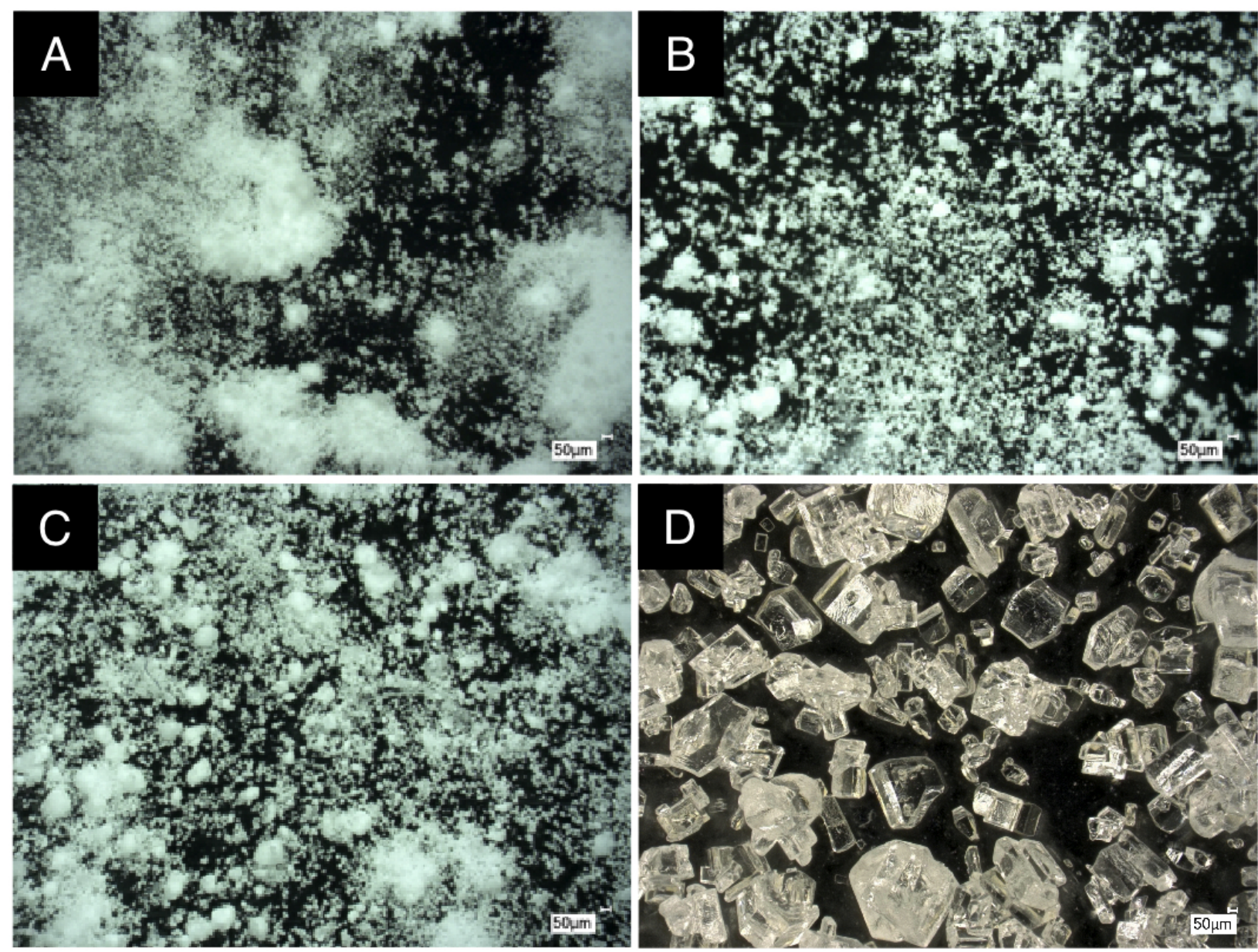

264 Figure 3. Digital microscopy images at $\times 100$ magnification of different particle size batches of

265 levonorgestrel. $A-d_{90} \leq 6.11 \mu \mathrm{m}, \mathrm{B}-\mathrm{d}_{90} \leq 294 \mu \mathrm{m}, \mathrm{C}-\mathrm{d}_{90} \leq 384 \mu \mathrm{m}$ and $\mathrm{D}-\mathrm{d}_{90} \leq 542 \mu \mathrm{m} .50$

$266 \mu \mathrm{m}$ size bars $(\vdash \dashv)$ are presented bottom right in each photograph. Particle size values are also

267 summarized in Table 2. 

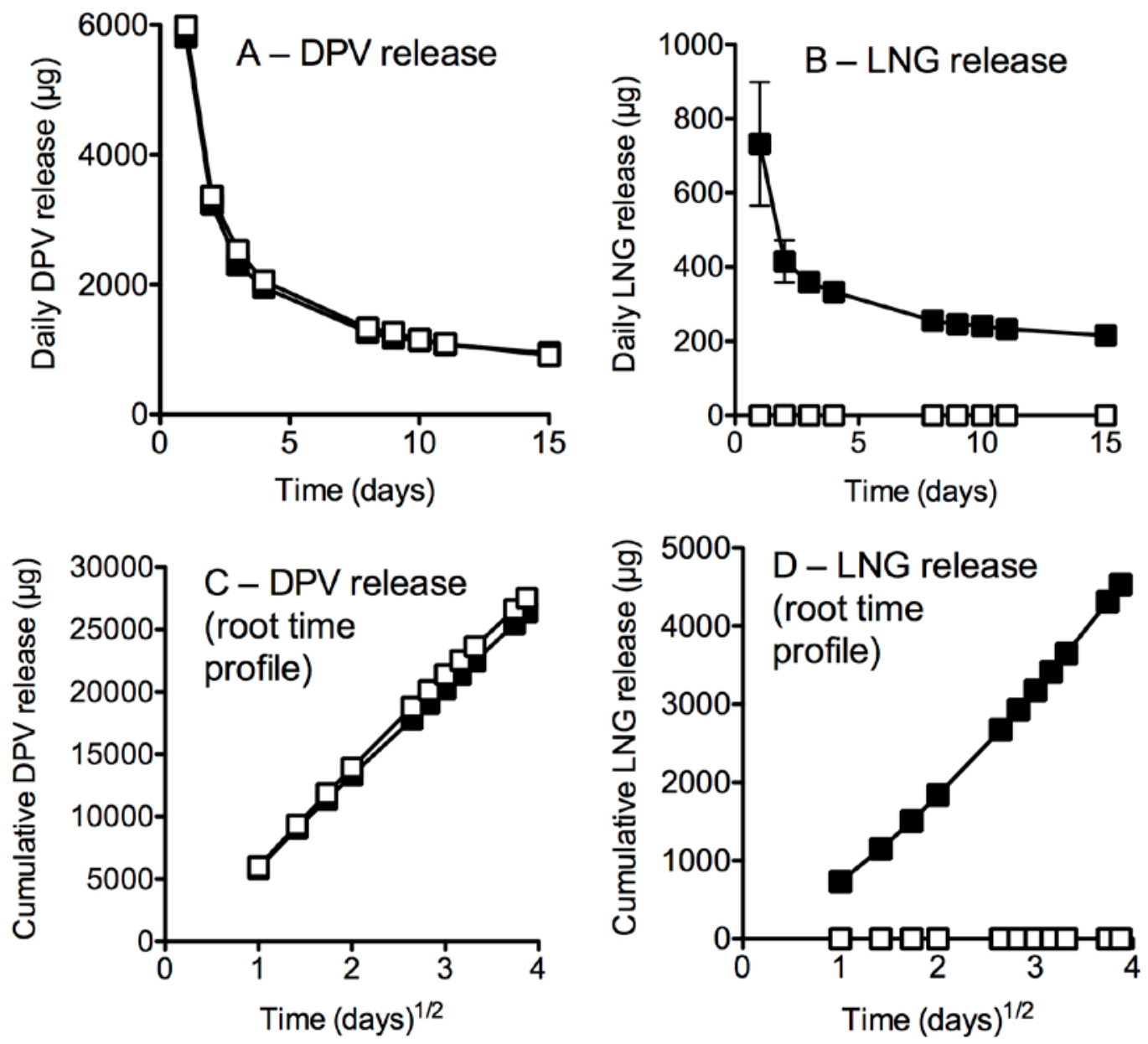

268

Ring 200mg DPV + 32mg nmLNG

$\square$ - Ring 200mg DPV + 32mg mLNG

269

270 Figure 4. Mean daily release versus time and mean cumulative release versus root time profiles

271 for matrix-type MED-4870 silicone elastomer vaginal rings containing $200 \mathrm{mg}$ micronized

272 dapivirine and $32 \mathrm{mg}$ of either micronised levonorgestrel or non-micronised levonorgestrel

$273(n=4)$. A - Daily dapivirine release vs. time plots. B - Daily levonorgestrel release vs time plots. C

$274-$ Cumulative dapivirine release vs. root time plots. D - Cumulative levonorgestrel vs. root time

275 plots. DPV - dapivirine. LNG - levonorgestrel. All rings were manufactured by injection molding 276 at $160{ }^{\circ} \mathrm{C}$ for $90 \mathrm{~s}$. 
277 In order for effective drug release to occur from a silicone elastomer vaginal ring device,

278 incorporated drug substances must permeate through the bulk of the silicone elastomer matrix.

279 This permeation process can be considered as two discrete steps - dissolution of the drug in

280 the silicone elastomer, followed by molecular diffusion of the solvated drug molecules through

281 the silicone elastomer [30]. Both the degree of solubility and the rate of diffusion of drugs

282 incorporated into silicone elastomers are temperature-dependent, and are expected to

283 increase significantly at the high temperatures commonly used in injection molding

284 manufacture of silicone elastomer vaginal rings. Solubility of the drug in the silicone elastomer

285 matrix also increases the proportion of levonorgestrel molecules available for chemical binding

286 via the hydrosilylation reaction. Thus, a rational explanation for the differences observed in

287 release between micronised levonorgestrel and non-micronised levonorgestrel is that the

288 micronized form of the drug exhibits faster rate of solubilization in the silicone elastomer at the

$289160{ }^{\circ} \mathrm{C}$ manufacturing temperature (levonorgestrel melting point is $240{ }^{\circ} \mathrm{C}$ ), such that a

290 significant proportion of the levonorgestrel molecules subsequently react with the hydrosilane

291 groups within the silicone elastomer. By contrast, the observation that vaginal rings containing

$29232 \mathrm{mg}$ non-micronised levonorgestrel exhibited significant levonorgestrel release was

293 attributed to the reduced rate of dissolution associated with the larger levonorgestrel particles

294 and, in turn, reduced levonorgestrel binding to the silicone elastomer. This observation concurs

295 with the well-established principle of increased surface area leading to increased rate of

296 dissolution, as expressed in the Noyes-Whitney equation [31]. 
299 To explore this levonorgestrel-binding hypothesis further, additional solvent extraction 300 experiments were conducted using levonorgestrel-loaded silicone elastomer slabs 301 manufactured under different cure conditions. No levonorgestrel could be recovered by solvent 302 extraction from MED-4870 silicone elastomer slabs containing $0.4 \% \mathrm{w} / \mathrm{w}$ micronised 303 levonorgestrel manufactured at (i) various cure temperatures $\left(120-200^{\circ} \mathrm{C}\right.$ ) and a fixed cure 304 time (10 $\mathrm{min})$ (Figure $5 \mathrm{~A})$ and (ii) various cure times (1.5-120 min) and a fixed cure temperature $305\left(160^{\circ} \mathrm{C}\right)$ (Figure 5B). By contrast, MED-4870 silicone elastomer slabs containing 0.4\% w/w non306 micronised levonorgestrel produced measurable recovery of levonorgestrel by solvent 307 extraction at all but the most extreme cure conditions (i.e. $200{ }^{\circ} \mathrm{C}$ at $10 \mathrm{~min}$ and $120 \mathrm{~min}$ at 160 $308{ }^{\circ} \mathrm{C}$; Figures $6 \mathrm{~A}$ and 6B, respectively). In fact, the non-micronised levonorgestrel MED-4870 slabs 309 showed a clear trend of decreasing levonorgestrel recovery values as a function of both 310 increasing cure temperature (Figure 5A) and increasing cure time (Figure 5B). These data and 311 trends strongly support the hypothesis that levonorgestrel binding to the silicone elastomer 312 system is dependent on its solubilization in the elastomer. 


\section{MED-4870}

A

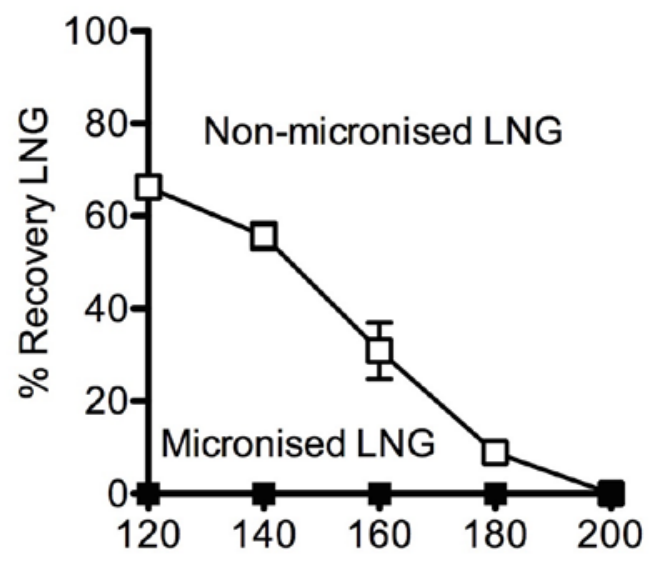

Cure Temperature $\left({ }^{\circ} \mathrm{C}\right)$ for $10 \mathrm{~min}$
B

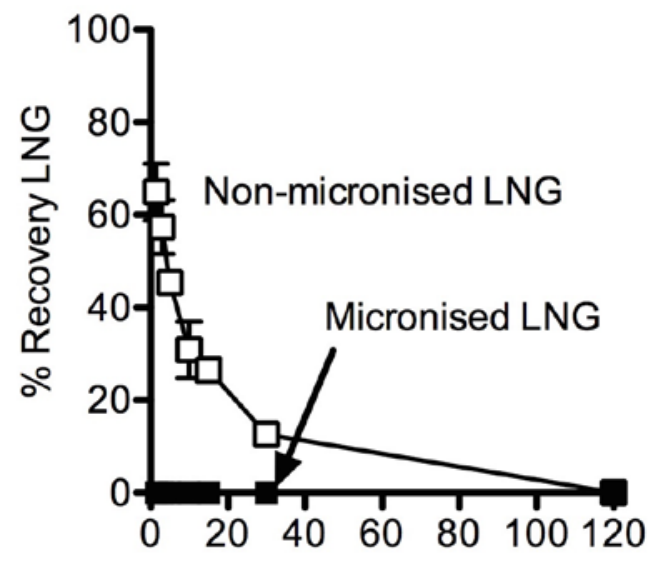

Cure Time $(\mathrm{min})$ at $160^{\circ} \mathrm{C}$

\section{DDU-4320}

C

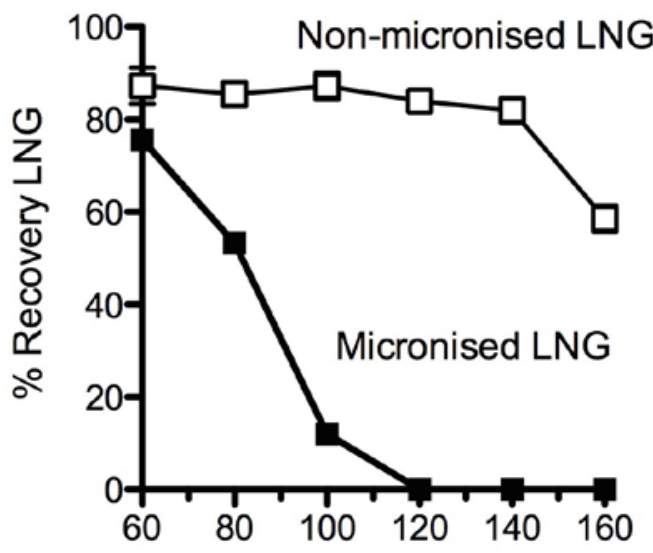

Cure Temperature $\left({ }^{\circ} \mathrm{C}\right)$ for $7 \mathrm{~min}$

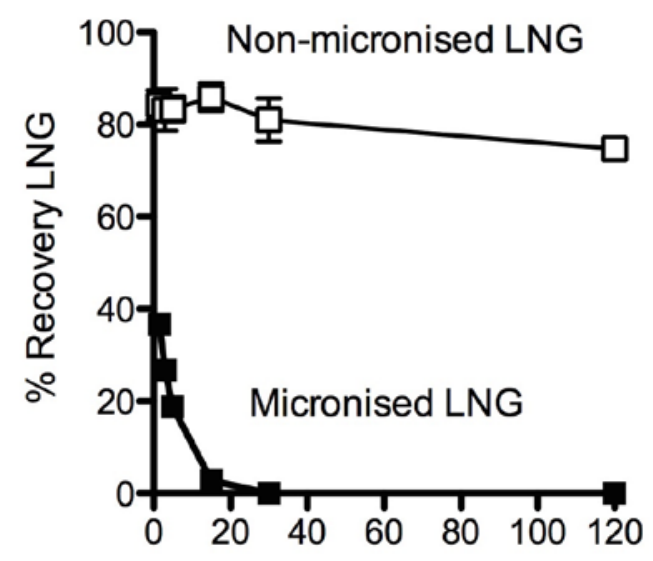

Cure Time $(\min )$ at $100^{\circ} \mathrm{C}$

314 Figure 5. Influence of cure temperature and cure time on percentage recovery of micronized

315 and non-micronised levonorgestrel from MED-4870 and DDU-4320 silicone elastomer slabs.

316 Levonorgestrel loading for all samples was $0.4 \% \mathrm{w} / \mathrm{w}$ (equivalent to $32 \mathrm{mg}$ in a human-sized

317 vaginal ring device). Each data point represents the mean \pm SD of 4 replicates. Error bars are 318 often smaller than the plot symbols. 
320 For the MED-4870 system, the highest recovery of levonorgestrel (66.2\%) was measured for the

321 non-micronised levonorgestrel slabs prepared at the $120^{\circ} \mathrm{C} / 10$ min cure condition (Figure 5A).

322 This value is significantly below the range of acceptable assay values (85-115\%) commonly

323 specified for a Phase 1 product. Although higher values for levonorgestrel recovery could be

324 achieved for the MED-4870 system by curing at lower temperatures, this would lead to

325 significantly increased process cycle times such that scaled manufacture would be impractical.

326 For example, in additional experiments, we demonstrated that MED-4870 silicone elastomer

327 containing $0.4 \% \mathrm{w} / \mathrm{w}$ non-micronised levonorgestrel can be cured at $80{ }^{\circ} \mathrm{C}$ for $2.5 \mathrm{~h}$ to give a

328 levonorgestrel recovery value of $86.2 \%$. However, injection molding cycle times less than 2 min

329 are preferable. Reducing cure time is also not an option, since $90 \mathrm{~s}$ at $160{ }^{\circ} \mathrm{C}$ was the minimum

330 cure condition required to produce a ring or slab device having sufficient mechanical properties

331 for demolding.

332

333 An alternative medical grade addition-cure silicone elastomer system, DDU-4320, was selected

334 for testing based on its recommended low cure temperature characteristics. For silicone

335 elastomer slabs containing micronised levonorgestrel and prepared at $60{ }^{\circ} \mathrm{C}$ for $7 \mathrm{~min}$,

336 levonorgestrel recovery was $75.6 \%$, with values decreasing as cure temperature was increased

337 (Figure 5C). However, no levonorgestrel recovery was obtained for cure temperatures $120{ }^{\circ} \mathrm{C}$

338 and above (Figure 5C). For the non-micronised levonorgestrel DDU-4320 samples,

339 levonorgestrel recovery values were significantly higher $\left(87.3 \%\right.$ at $60{ }^{\circ} \mathrm{C}$ declining to $58.5 \%$ at

$340160{ }^{\circ} \mathrm{C}$; Figure $5 \mathrm{C}$ ) compared to those for micronised levonorgestrel, mimicking the trend

341 observed previously with the high temperature cure MED-4870 system. Selecting an 
342 intermediate cure temperature of $100{ }^{\circ} \mathrm{C}$ for this DDU-4320 system, the effect of varying cure

343 time has a greater influence on the micronised levonorgestrel compared with the non-

344 micronized material (Figure 5D). Importantly, the DDU-4320 slabs containing non-micronised

345 levonorgestrel offered levonorgestrel recovery values close to the specified range for content 346 assay / uniformity (90-110\% label claim).

348 For comparison, incorporation of $0.4 \% \mathrm{w} / \mathrm{w}$ micronised levonorgestrel and non-micronised 349 levonorgestrel into MED-6382 silicone elastomer (a medical grade tin-catalysed condensation 350 cure system) produced levonorgestrel recovery values of 98.9 and $100.8 \%$, respectively.

351 However, this condensation-cure silicone elastomer produces isopropanol as a by-product of 352 the curing reaction. Both levonorgestrel and dapivirine are highly soluble in isopropanol, and 353 therefore these condensation cure silicone elastomers are not preferred in order to avoid drug 354 migration to the ring surface as isopropanol migrates to the vaginal ring surface and evaporates $355[17]$.

357 Initially, the influence of levonorgestrel particle size on the extent of binding was tested using a 358 single batch of micronised levonorgestrel and non-micronised levonorgestrel (Batches 1 and 4, 359 respectively; Table 2; Figure 3; supplied by CHEMO). Two additional levonorgestrel materials 360 (Batches 2 and 3) were sieved at source so that particles intermediate in size could be tested 361 (Table 2). Silicone elastomer DDU-4320 slabs containing $0.4 \% \mathrm{w} / \mathrm{w}$ levonorgestrel were 362 prepared at $100{ }^{\circ} \mathrm{C}$ for $90 \mathrm{~s}$ for each levonorgestrel batch. As expected, the levonorgestrel 363 recovery values for these sieved levonorgestrel materials (56.7\% and 55.6\%; Table 2) lie 
364 between the values for the previously tested non-micronised levonorgestrel and micronised 365 levonorgestrel (98.4\% and $41.3 \%$, respectively; Table 2$)$, further supporting the solubilisation 366 hypothesis. The similarity in levonorgestrel recovery values for Batches 2 and 3 is most likely 367 due to the equivalence in d10 values (despite the very different d90 and d50 values), since the 368 fines are expected to contribute disproportionately to the overall surface area of the material.

370 The percentage recovery of levonorgestrel from DDU-4320 silicone elastomer vaginal rings 371 cured at $90^{\circ} \mathrm{C}$ for 3 min increased $(55.0-84.9 \%)$ as the loading amount of micronised 372 levonorgestrel incorporated into the device was increased from 25 to 100 and $400 \mathrm{mg}$ (Table 3).

373 This trend is consistent with the proposed solubility hypothesis, since progressively smaller 374 fractions of the total levonorgestrel loading are expected to dissolve and bind to the silicone 375 elastomer as the levonorgestrel loading is increased. For the vaginal rings containing non376 micronised levonorgestrel, recoveries were close to $100 \%$ irrespective of levonorgestrel loading 377 (Table 3). These recovery values are also slightly higher than those predicted based on the 378 previous slab data (Figure 5). This is likely attributed to a temperature-insulating effect for drug 379 particles located in the bulk of the vaginal rings, attributed to the larger volume and/or the 380 smaller surface area-to-volume ratio associated with the vaginal ring devices compared with 381 slabs. This insulation effect is further illustrated by the data presented in Supplementary 382 Information in which reported non-micronised levonorgestrel recovery values were lower (but 383 not significantly) for slabs compared with vaginal rings, and where both are manufactured 384 under the same cure conditions. 
Table 3. Percentage recovery levonorgestrel from matrix-type DDU-4320 silicone elastomer

387 vaginal rings cured at $90{ }^{\circ} \mathrm{C}$ for $3 \mathrm{~min}$ and containing different amounts of micronized and non388 micronised levonorgestrel. Each levonorgestrel recovery value is the mean of four replicates 389 and reported errors denote standard deviations.

\begin{tabular}{lcc}
\hline $\begin{array}{l}\text { Levonorgestrel } \\
\text { loading } \\
(\mathrm{mg}, \% \mathrm{w} / \mathrm{w})\end{array}$ & \% Levonorgestrel Recovery \\
\hline $25,0.3125$ & $99.5 \pm 2.3$ & $55.0 \pm 5.8$ \\
$100,1.25$ & $96.1 \pm 6.9$ & $71.1 \pm 1.3$ \\
$400,5.00$ & $100.6 \pm 8.0$ & $84.9 \pm 4.8$ \\
\hline
\end{tabular}

392 MED-4870 and DDU-4320 addition-cure silicone elastomer systems are supplied as two-part 393 kits. Both parts contain the silicone elastomer base material, which comprises various vinyl394 functionalised (Figure 1B) and hydroxy-terminated polydimethylsiloxane molecules. Part A also 395 includes the platinum catalyst, while Part B also includes the poly(methylhydrosiloxane) 396 component that ultimately reacts with the vinyl-functionalised polydimethylsiloxane molecules 397 (Figure 1B). (Both parts also contain other components that are not pertinent to this 398 discussion.) Therefore, it is conceivable that addition of levonorgestrel to only one of the parts 399 might impact its propensity to bind when the two parts are subsequently mixed and cured.

400 Percentage levonorgestrel recovery values for slabs made with either MED-4870 or DDU-4320 401 and in which micronised levonorgestrel or non-micronised levonorgestrel is added to Part A 402 only, Part B only or to both Parts are reported in Figure 6. For DDU-4320 slabs, the addition of 403 levonorgestrel to one, other or both parts of the silicone elastomer system had no impact on 
404 levonorgestrel recovery, although, as expected, differences in levonorgestrel recovery were 405 observed for the micronized versus non-micronized materials (Figure 6B). However, addition of 406 non-micronised levonorgestrel to Part B only of MED-4870 resulted in increased levonorgestrel 407 recovery (57\%) compared to adding it to Part A only (33\%) or to both parts (30\%) (Figure 6A). As 408 previously observed, levonorgestrel recovery values were significantly higher for DDU-4320 409 compared to MED-4870, and for non-micronised levonorgestrel compared to micronised 410 levonorgestrel. 

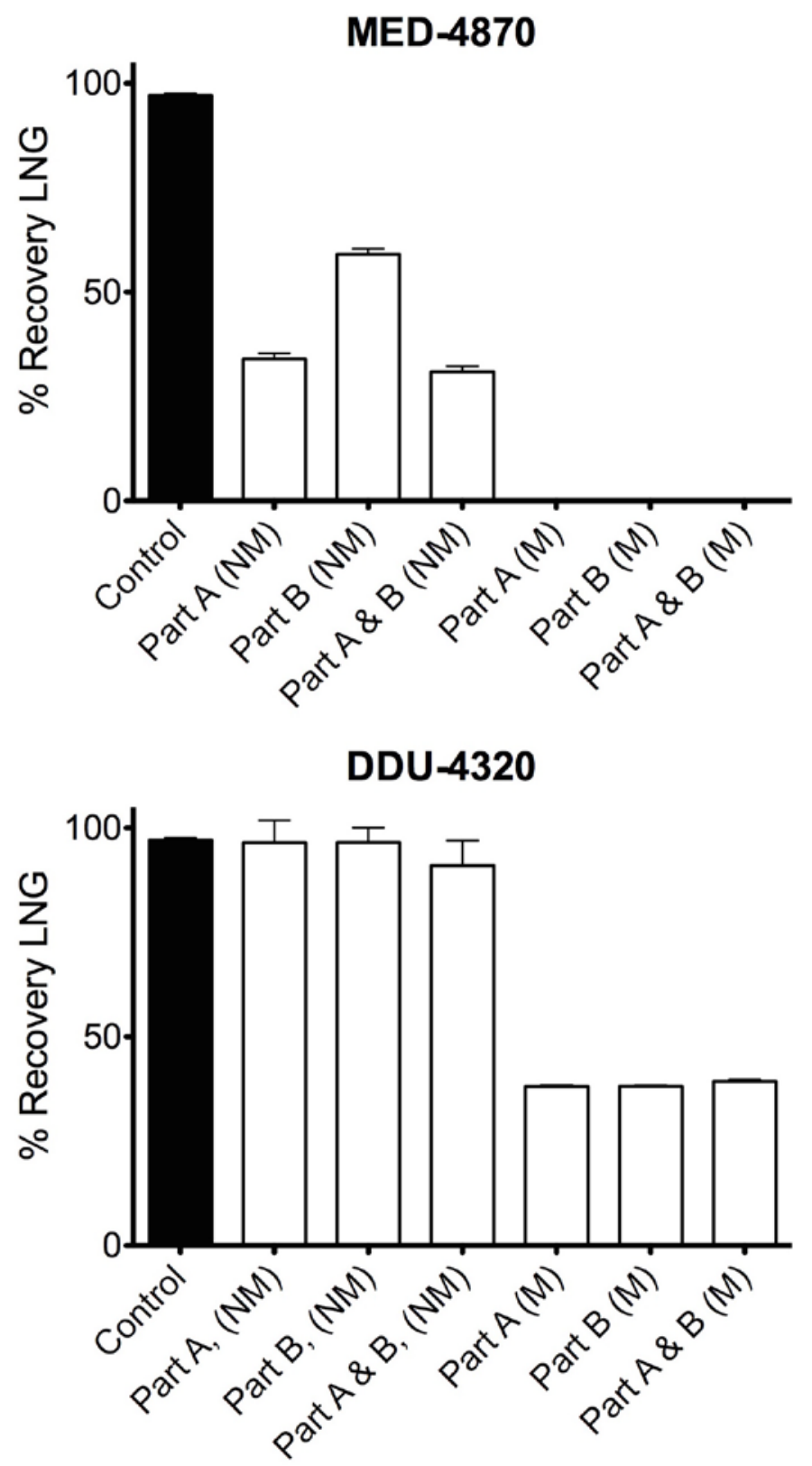

412 Figure 6. Influence of order of addition of levonorgestrel upon levonorgestrel recovery from

413 MED-4870 and DDU-4320 silicone elastomer slabs ( $n=4)$. MED-4870 slabs were cured at $160{ }^{\circ} \mathrm{C}$

414 for 90 s. DDU-4320 slabs were cured at $100{ }^{\circ} \mathrm{C}$ for 90 s. Part A - levonorgestrel added only to

415 Part A of the silicone elastomer prior to curing; Part B - levonorgestrel added only to Part B of

416 the silicone elastomer only prior to curing; Part A \& B - equal amounts of levonorgestrel added 
417 to both parts prior to curing; NM - non-micronised levonorgestrel, $\mathrm{M}$ - micronised

418 levonorgestrel.

420 Silicone oils are sometimes used as dispersing agents for addition of drug powders to silicone 421 elastomer systems. The impact of dispersing levonorgestrel in MED-360 silicone oil prior to 422 manufacture of DDU-4320 silicone elastomer slabs was investigated for selected cure 423 conditions. The results, presented in Supplementary Information, show that levonorgestrel 424 recovery was typically $4-10 \%$ higher with use of the silicone oil. However, at the highest cure 425 temperature tested $\left(160{ }^{\circ} \mathrm{C}\right)$, no significant difference in levonorgestrel recovery was observed 426 for either non-micronised or micronised levonorgestrel.

428 In an additional set of experiments, silicone elastomer DDU-4320 slabs containing $1 \% \mathrm{w} / \mathrm{w}$ 429 dapivirine, non-micronised levonorgestrel or micronised levonorgestrel and prepared via 430 injection molding at $90{ }^{\circ} \mathrm{C}$ for $3 \mathrm{~min}$ were subjected to drug extraction via dichloromethane to 431 measure drug recovery followed by swelling in hexane to determine the silicone elastomer 432 crosslinking density. Similar to previous results, percentage drug recovery decreased in the 433 order dapivirine (99.3\%) > non-micronised levonorgestrel $(87.6 \%)>$ micronised levonorgestrel 434 (79.4\%), reflecting the extent of reaction of each drug with the hydrosilane groups in the 435 silicone elastomer system under the conditions of cure (Figure 7A). Following drug extraction, 436 the slabs were dried and reweighed; the values for total percentage mass extracted are 437 presented in Figure 7B. The $\sim 5 \%$ mass loss observed for the control sample (containing no drug) 438 was attributed to the extraction of non-reactive silicone oil components in the silicone 
439 elastomer formulation. The same mass loss due to extraction of these oils was presumably also

440 observed in each the drug-loaded samples, with any additional mass loss due to extraction of

441 either non-bound drug or unreacted polydimethylsiloxane components. Interestingly, the

442 highest extraction mass was observed for the micronised levonorgestrel slab, which is counter-

443 intuitive if only the propensity for the micronised levonorgestrel crystalline material to rapidly

444 solubilize and undergo hydrosilylation reaction within the silicone elastomer is considered.

445 However, these levonorgestrel molecules compete with the vinyl-functionalised

446 polydimethylsiloxane molecules in the silicone elastomer system for reaction with the hydride-

447 functionalised polydimethylsiloxane molecules. In this way, the overall crosslink density is

448 reduced in the silicone elastomer and there is increased opportunity for extraction of non-

449 reactive polydimethylsiloxane molecules. This effectively explains the trends in percentage

450 mass extraction values (Figure 7B). An entirely similar trend is also observed for the percentage

451 swelling values (in dichloromethane; Figure 7C), adding further support to the different impact

452 of the various drug molecules on the silicone elastomer crosslinking density. Conventionally,

453 crosslinking densities in silicone elastomer systems are measured by swelling samples in hexane

454 rather than dichloromethane. Subsequent placement of the silicone elastomer slabs into

455 hexane resulted in minimal additional mass loss (Figure 7D), and confirmed the previous trend

456 in crosslinking density obtained with dichloromethane (compare Figures $8 \mathrm{C}$ and $7 \mathrm{E}$ ). The plot of

457 mean percentage mass extraction verses mean percentage swelling for the various silicone

458 elastomer slab formulations showed a linear positive correlation $\left(r^{2}=0.972\right)$ (Figure 7F). 
A

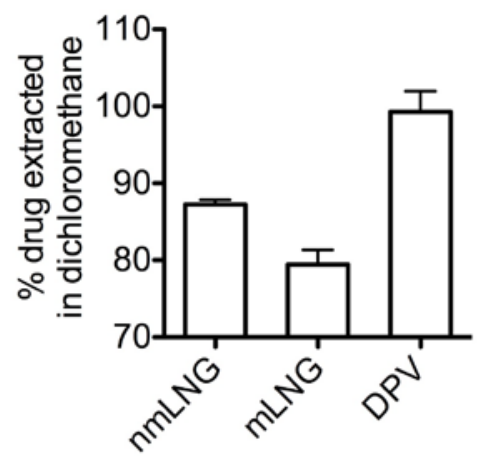

D

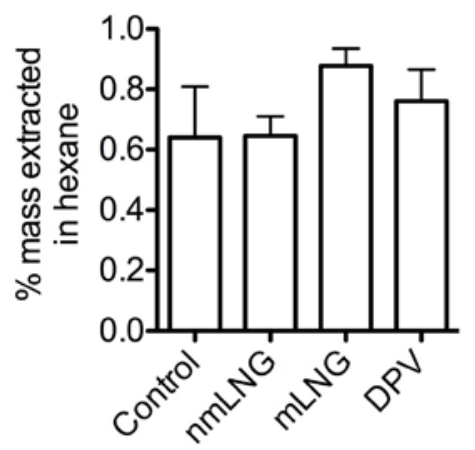

B

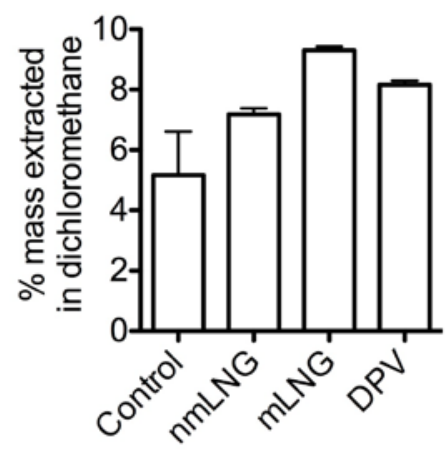

E

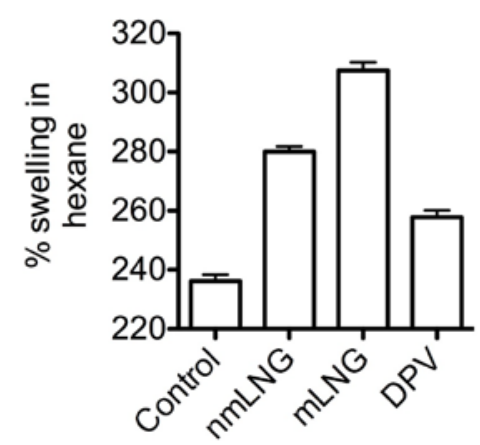

C

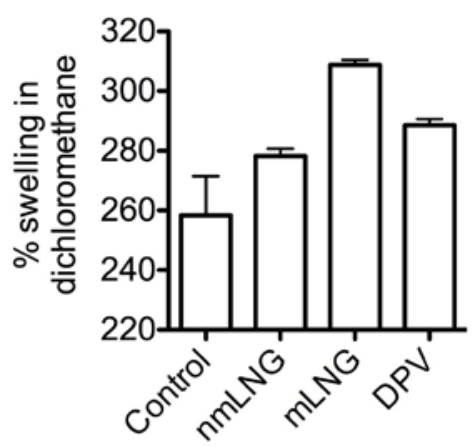

$\mathbf{F}$

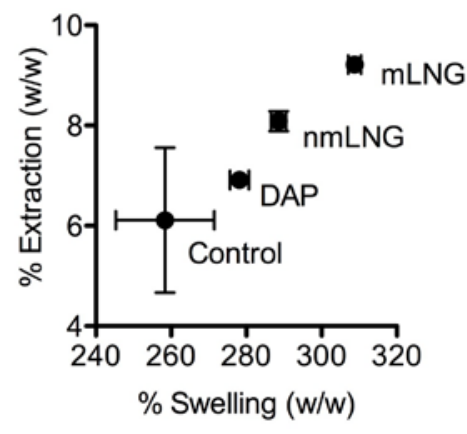

460

461 Figure 7. Results of hexane swelling experiments to assess degree of crosslinking in silicone

462 elastomer slabs after extraction of non-bound drug $(n=4)$. nmLNG - non-micronised

463 levonorgestrel; mLNG - micronised levonorgestrel; DPV - dapivirine. A - Percentage drug

464 extraction in dichloromethane. B - Percentage mass extraction in dichloromethane. C -

465 Percentage swelling in dichloromethane. D - Percentage mass extraction in dichloromethane. E

466 - Percentage swelling in hexane. F - \% Extraction (w/w) vs. swelling (w/w) in hexane.

468 Given the observation that levonorgestrel covalently binds to the silicone elastomer during 469 cure, oscillatory rheology was used to monitor changes in storage modulus (a measure of the 470 stored energy, representing the elastic portion) of different non-micronised levonorgestrel, 
471 micronised levonorgestrel and dapivirine-loaded DDU-4320 silicone elastomer systems during

472 the curing process. Consistent with previous reports [28], the storage modulus for each

473 formulation increased with time, as exemplified by the rheograms for the non-micronised

474 levonorgestrel formulations presented in Figure $8 \mathrm{~A}$ and reflecting the increase in viscosity as

475 cure progresses. However, the relationship between storage modulus and drug concentration is

476 not simple. For example, for the non-micronised levonorgestrel formulations, storage modulus

477 increased in the concentration rank order $1 \%<5 \% \cong 10 \% \cong 15 \%<0 \%<20 \%$ (Figure 8B).

478 This trend reflects the interplay between levonorgestrel's ability to inhibit cure (via 479 dissolution and reaction with the silicone elastomer) and to act as mechanical filler. For 480 silicone elastomer formulations having relatively low levonorgestrel concentrations (e.g. $4811 \% \mathrm{w} / \mathrm{w}$ ), cure inhibition predominates and the storage modulus is reduced significantly 482 compared to the control formulation $(0 \%$ levonorgestrel). However, at higher 483 levonorgestrel loadings (e.g. $20 \% \mathrm{w} / \mathrm{w}$ ), the cure inhibition effect is masked by the 484 mechanical filler effect, as evidenced by storage modulus values significantly greater than 485 the control formulation (Figure 8A). By plotting the value of the storage modulus at $800 \mathrm{~s}$ 486 cure time versus drug concentration (Figure 8B), it is apparent that this complex interplay 487 exists for both micronised levonorgestrel and non-micronised levonorgestrel. 488 Unsurprisingly, the extent of cure inhibition is generally lower for the slower-dissolving 489 (less prone to binding) non-micronised levonorgestrel samples. Dapivirine, on the other 490 hand, lacks the chemical functionality to react with the silicone elastomer components and 491 therefore does not exhibit the initial decline in storage modulus at low dapivirine 492 concentrations compared with the non-medicated control. Instead, dapivirine acts solely as 
493 a mechanical filler by increasing the storage modulus at relatively high dapivirine 494 concentrations (Figure 8B).

495
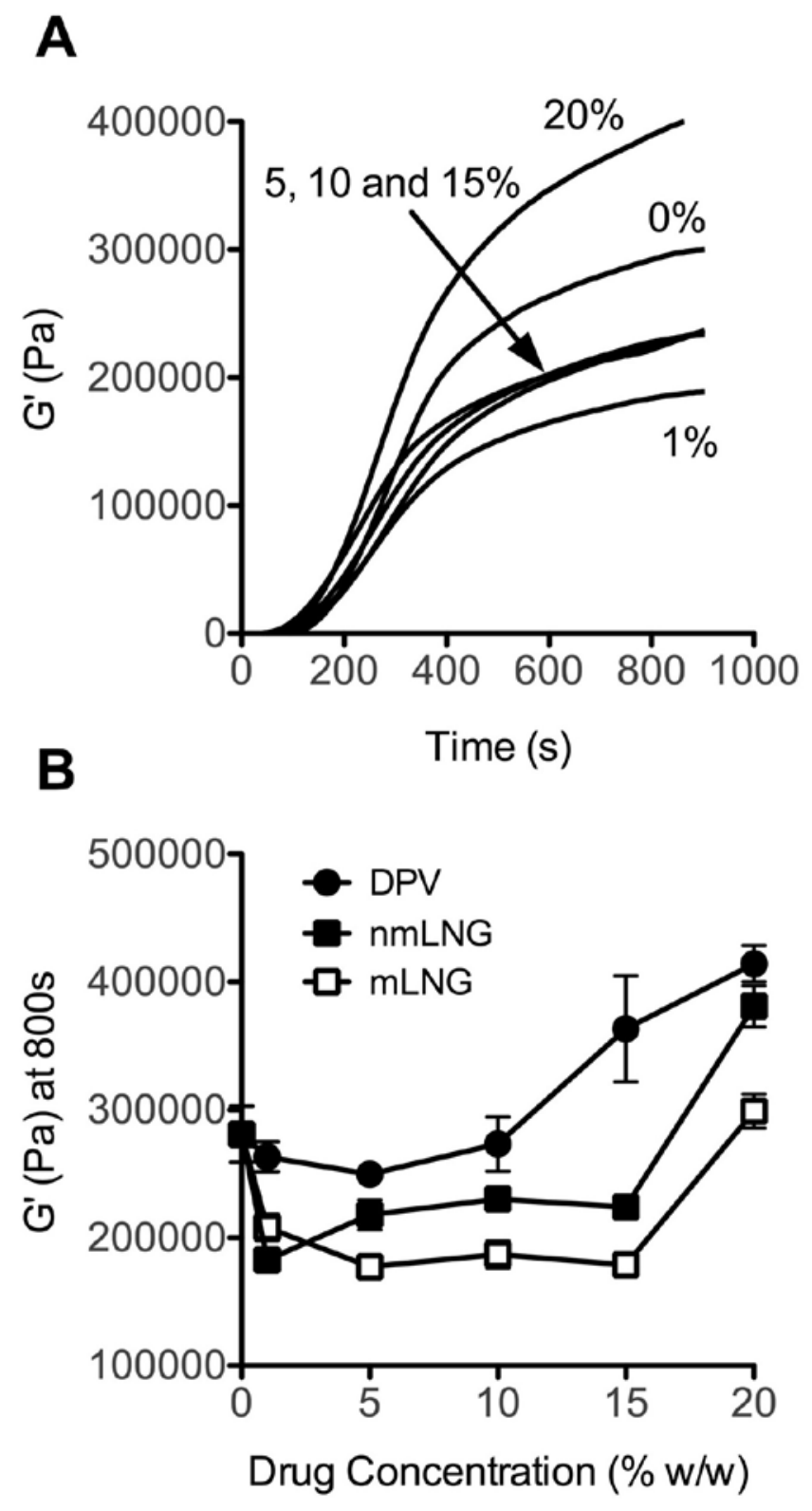

496

497 Figure 8. A - Oscillatory rheograms (storage modulus versus time) following the cure process 498 for silicone elastomer samples containing different concentrations of non-micronised 499 levonorgestrel. Plot symbols and error bars represent the mean and standard deviation of four 
500 replicates. Similar rheograms were obtained for samples containing dapivirine and micronised

501 levonorgestrel. B - Graph showing storage modulus at 800 s versus concentration of dapivirine, 502 non-micronised levonorgestrel and micronised levonorgestrel.

503

504 3.4. In vitro release of dapivirine and levonorgestrel from rings manufactured under optimised 505 cure conditions

506 Finally, armed with the knowledge that silicone elastomer type, cure temperature, cure time, 507 levonorgestrel loading and levonorgestrel particle size all have a role to play in determining the 508 extent of levonorgestrel binding, additional dapivirine+levonorgestrel matrix-type DDU-4320

509 silicone elastomer vaginal rings were fabricated under processing conditions $\left(94^{\circ} \mathrm{C}\right.$ cure

510 temperature and 90 s cure time) selected to minimise levonorgestrel binding. The vaginal rings,

511 all containing 200 mg micronized dapivirine and either 32, 48 or 64 mg non-micronised

512 levonorgestrel were then tested for in vitro release and content assay. The 92-day in vitro

513 dapivirine and levonorgestrel release profiles are presented in Figure 9. Dapivirine release

514 characteristics over the first 15 days were entirely similar to those measured for the original

515 MED-4870 vaginal rings (Figure 4). Dapivirine release on day 90 was in the range 325-342 $\mu \mathrm{g}$ for

516 all vaginal ring formulations (Figure 9A) and dapivirine content assay values matched the label

517 claim (99.3-100.4\%). For DDU-4320 vaginal rings manufactured using the optimised cure

518 conditions, the mean day 1 amount of levonorgestrel released from the $200 \mathrm{mg}$ dapivirine +32

519 mg non-micronised levonorgestrel vaginal ring was $1219 \pm 37 \mu \mathrm{g}$ (Figure 9B), a significant

520 increase over the $732 \pm 166$ mean day 1 value for the MED-4870 rings (Figure 4B) and a

521 consequence of a reduction in the extent of levonorgestrel binding. For the same DDU-4320 
522 vaginal ring formulation, day 90 levonorgestrel release was $85 \pm 5 \mu$ g (Figure 9B). The total

523 percentage DPV release was approximately 33\% (66 mg from initial $200 \mathrm{mg}$ loading), while total

524 percentage $L N G$ release ranged from $54 \%-64 \%$ depending on initial drug loading.

525

526 These 92-day release values for both dapivirine and levonorgestrel bode well for a viability of a 527 3-month MPT vaginal ring product offering both HIV prevention and contraception. As 528 expected, increasing the non-micronised levonorgestrel loading within the DDU-4320 vaginal 529 ring from $32 \mathrm{mg}$ to either $48 \mathrm{mg}$ or $64 \mathrm{mg}$ produced increases in the levonorgestrel release rate 530 proportional to the loading (Figure 9B and 9D). Critically, the percentage levonorgestrel 531 recovery values in the content assay $(93.0 \%, 94.4 \%$ and $95.9 \%$ for the $200 / 32,200 / 48$ and $532200 / 64$ vaginal rings, respectively) now fall within the $90-110 \%$ label claim range. 

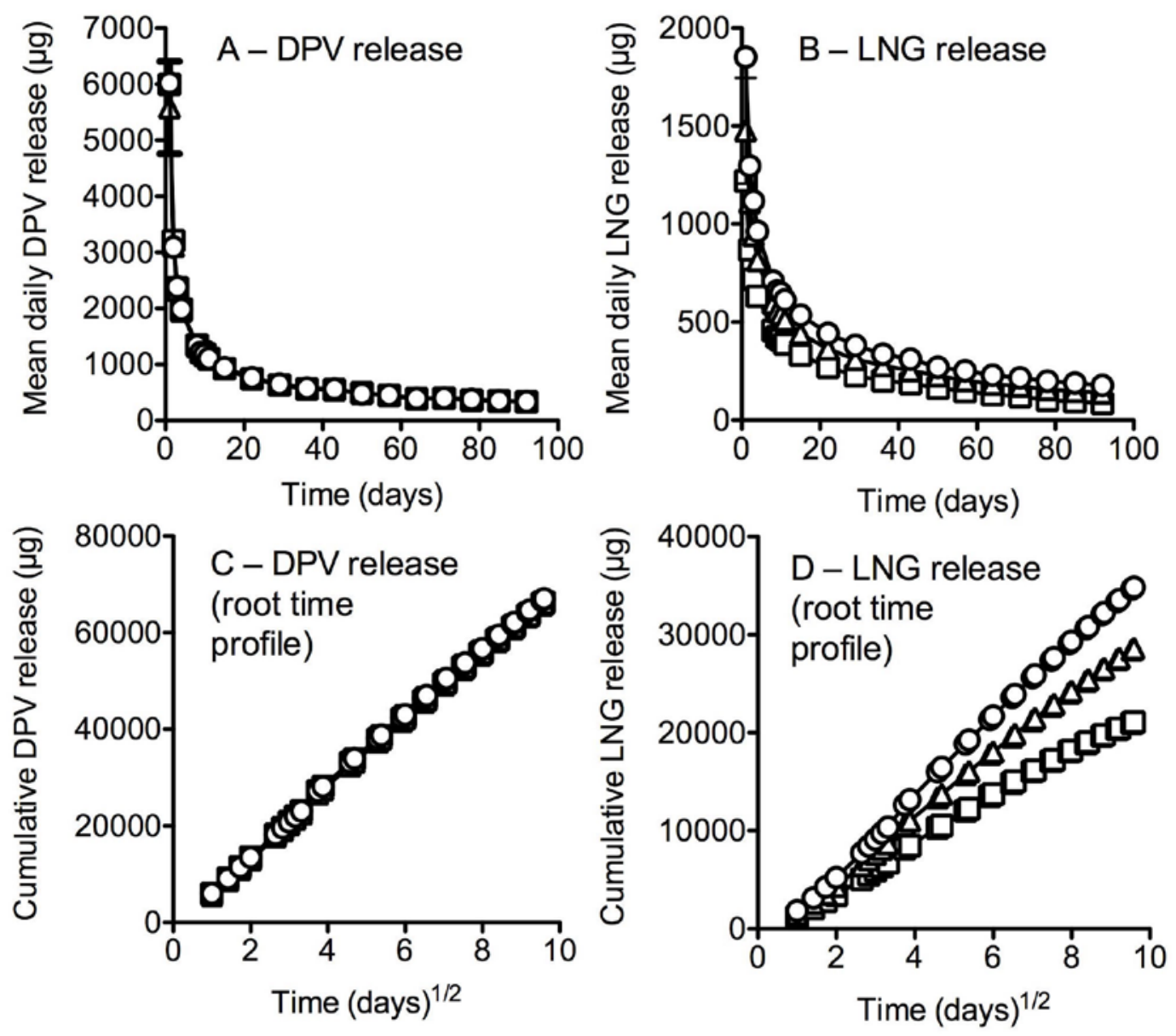
- o. $200 \mathrm{mg}$ DPV $+64 \mathrm{mg} n \mathrm{mLNG}$
$-\Delta 200 \mathrm{mg}$ DPV + 48mg nmLNG
ㅁ. 200mg DPV + 32mg nmLNG

534 Figure 9. In vitro daily release vs. time graph for release of micronised dapivirine and non-

535 micronised levonorgestrel from human-type, silicone elastomer, matrix vaginal rings into 1:1

536 isopropanol/water. Cure conditions for these rings were $94{ }^{\circ} \mathrm{C}$ for $90 \mathrm{~s}$. Daily release plot

537 symbols and error bars (mostly not visible due to being smaller in size than the plot symbol)

538 represent the mean and standard deviation of six replicates.

\section{Conclusions}


541 Chemical reaction between the ethynyl functional group in levonorgestrel and the hydrosilane

542 functional groups in addition-cure silicone elastomers takes place via the same hydrosilylation

543 reaction used to cure the silicone elastomer, and leads to irreversible covalent binding of

544 levonorgestrel molecules to the elastomer. The extent of levonorgestrel binding depends upon

545 the processing conditions, including cure temperature, cure time, levonorgestrel particle size,

546 levonorgestrel loading and the type of silicone elastomer. This API-binding phenomenon raises

547 challenges for the future development of certain silicone elastomer drug delivery devices that

548 incorporate drug molecules with similar chemically reactive functional groups, including a

549 significant number of other steroid molecules. 


\section{AUTHOR INFORMATION}

\section{Corresponding Author}

552 *School of Pharmacy, Medical Biology Centre, Queen's University Belfast, Belfast BT9 7BL, 553 United Kingdom. Tel: +44 (0)28 9097 2319. E-mail: k.malcolm@qub.ac.uk

\section{Author Contributions}

556 All authors contributed to the design of experiments and analysis of the data. D.J.M, P.B, C.F.M 557 and S.K conducted the experimental work. The manuscript was drafted by R.K.M and D.J.M, 558 with input from other authors.

$560 \quad$ Notes

561 The authors declare no competing financial interest.

562

\section{ACKNOWLEDGEMENTS}

564 The work was supported by a grant to Queen's University Belfast from The International 565 Partnership for Microbicides, through generous support from the Ministry of Foreign Affairs of

566 the Netherlands and the American people through the United States Agency for International 567 Development (USAID) through the President's Emergency Plan for AIDS Relief (PEPFAR). 568 Sandeep Kumar's postgraduate studies were funded by a National Overseas Scholarship from 569 the Government of India. 


\section{REFERENCES}

571 [1] P.J. Dziuk, B. Cook, Passage of steroids through silicone rubber., Endocrinology. 78 (1966) 208-11.

[2] R.K. Malcolm, R.S. Veazey, L. Geer, D. Lowry, S.M. Fetherston, D.J. Murphy, et al., Sustained release of the CCR5 inhibitors CMPD167 and maraviroc from vaginal rings in

[3] R.K. Malcolm, A.D. Woolfson, C.F. Toner, R.J. Morrow, S.D. Mccullagh, Long-term, controlled release of the HIV microbicide TMC120 from silicone elastomer vaginal rings., J. Antimicrob. Chemother. 56 (2005) 954-6.

[4] S.M. Fetherston, P. Boyd, C.F. McCoy, M.C. Mcbride, K. Edwards, S. Ampofo, et al., A silicone elastomer vaginal ring for HIV prevention containing two microbicides with different mechanisms of action., Eur. J. Pharm. Sci. 48 (2012) 406-415.

[5] S.M. Fetherston, L. Geer, R.S. Veazey, L. Goldman, D.J. Murphy, T.J. Ketas, et al., Partial protection against multiple RT-SHIV162P3 vaginal challenge of rhesus macaques by a

[6] R.K. Malcolm, K.-L. Edwards, P. Kiser, J. Romano, T.J. Smith, Advances in microbicide

[7] R.K. Malcolm, S.M. Fetherston, C.F. McCoy, P. Boyd, I. Major, Vaginal rings for delivery of HIV microbicides., Int. J. Womens. Health. 4 (2012) 595-605.

[9] R. Singer, P. Mawson, N. Derby, A. Rodriguez, L. Kizima, R. Menon, et al., An intravaginal pharmacokinetic trial assessing delivery of dapivirine from a vaginal ring in healthy women, AIDS. (2014) 1. ring that releases the NNRTI MIV-150 reduces SHIV transmission in macaques., Sci. Transl. Med. 4 (2012) 150ra123.

[10] R.K. Malcolm, S.M. Fetherston, Delivering on MPTs : addressing the needs, rising to the challenges and making the opportunities, Contraception. 88 (2013) 321-325.

[11] R.K. Malcolm, P. Boyd, C.F. McCoy, D.J. Murphy, Beyond HIV microbicides: multipurpose prevention technology products., BJOG. 121 Suppl (2014) 62-9.

[12] C. Woodsong, J. Holt, B. Devlin, Z. Rosenberg, Current Status of Multipurpose Prevention Technology (MPT) Development, Curr. Obstet. Gynecol. Rep. 4 (2015) 43-52.

[13] J. Romano, J. Manning, A. Hemmerling, E. McGrory, B. Young Holt, Prioritizing multipurpose prevention technology development and investments using a target product profile., Antiviral Res. (2013) 1-7.

[14] D. Mansour, The benefits and risks of using a levonorgestrel-releasing intrauterine system for contraception, Contraception. 85 (2012) 224-234. 
[15] F.W. van Der Weij, The action of tin compounds in condensation-type RTV silicone rubbers, Die Makromol. Chemie. 181 (1980) 2541-2548.

[16] S.D. McCullagh, R.K. Malcolm, A.D. Woolfson, S.P. Gorman, D.S. Jones, J. Cuddy, Release kinetics of oleyl alcohol from a self-lubricating silicone biomaterial, J. Mater. Chem. 14 (2004) 1093.

[17] A.D. Woolfson, R.K. Malcolm, R.J. Gallagher, Design of a silicone reservoir intravaginal ring for the delivery of oxybutynin., J. Control. Release. 91 (2003) 465-76.

[18] A. Nel, S. Smythe, K. Young, K. Malcolm, C. McCoy, Z. Rosenberg, et al., Safety and pharmacokinetics of dapivirine delivery from matrix and reservoir intravaginal rings to

[19] L.N. Lewis, K.G. Sy, G.L. Bryant, P.E. Donahue, Platinum-catalyzed hydrosilylation of alkynes, Organometallics. 10 (1991) 3750-3759.

[20] M. Chauhan, B.J. Hauck, L.P. Keller, P. Boudjouk, Hydrosilylation of alkynes catalyzed by

[24] G. Schopflin, P. Fuchs, K.H. Kolb, Drug Excipient of Silicone Rubber, US4230686, 1980.

[25] B. Devlin, J. Holt, A. Brimer, J. Nuttall, K. Malcolm, S. Fetherston, et al., Combination

[21] S.E. Denmark, Z. Wang, Highly Stereoselective Hydrocarbation of Terminal Alkynes via PtCatalyzed Hydrosilylation/Pd-Catalyzed Cross-Coupling Reactions, Org. Lett. 3 (2001) 1073-1076.

[22] S. Ding, L.J. Song, L.W. Chung, X. Zhang, J. Sun, Y.D. Wu, Ligand-controlled remarkable regio- and stereodivergence in intermolecular hydrosilylation of internal alkynes: Experimental and theoretical studies, J. Am. Chem. Soc. 135 (2013) 13835-13842.

[23] K. Itami, K. Mitsudo, A. Nishino, J. Yoshida, Metal-Catalyzed Hydrosilylation of Alkenes and Alkynes Using Dimethyl(pyridyl)silane, J. Org. Chem. 67 (2002) 2645-2652. therapy intravaginal rings, US Patent Application No. 20150136143 A1, filed May 21 2015.

[26] Platinum-Catalyzed Silicone Drug Delivery Devices And Methods Of Use Thereof, US Provisional Patent Application No. 62/067,122, filed on October 22, 2014.

[27] D.N. Soulas, K.G. Papadokostaki, Experimental investigation of the release mechanism of proxyphylline from silicone rubber matrices, J. Appl. Polym. Sci. 120 (2011) 821-830.

[28] C. McConville, G.P. Andrews, T.P. Laverty, A.D. Woolfson, R.K. Malcolm, Rheological Evaluation of the Isothermal Cure Characteristics of Medical Grade Silicone Elastomers, J. Appl. Polym. Sci. 116 (2010) 2320-2327.

[29] T. Higuchi, Rate of release of medicaments from ointment bases containing drugs in suspension, J. Pharm. Sci. 50 (1961) 874-875.

[30] K. Malcolm, D. Woolfson, J. Russell, P. Tallon, L. Mcauley, D. Craig, Influence of silicone elastomer solubility and diffusivity on the in vitro release of drugs from intravaginal 
644

645

646

647 rings., J. Control. Release. 90 (2003) 217-25.

[31] A.A. Noyes, W.R. Whitney, The rate of solution of solid substances in their own solutions, J. Am. Chem. Soc. 19 (1897) 930-934. 